\title{
A pseudoleukemic blood differentiation in a 13-year-old child: an extraordinary presentation of Churg-Strauss syndrome
}

\author{
E. R. Mutsaers $\cdot$ R. Witteveen • \\ W. van den Bosch-Ruis • T. W. Kuijpers • \\ M. A. van Houten - J. M. van den Berg
}

Received: 8 July 2009 / Accepted: 14 August 2009 / Published online: 9 September 2009

(C) The Author(s) 2009. This article is published with open access at Springerlink.com

\begin{abstract}
Churg-Strauss syndrome (CSS) is a rare systemic vasculitis of the small- and medium-size vessels. It is mostly seen in elderly patients presenting as de novo asthma, eosinophilia, and vasculitic organ involvement. In childhood, CSS is extremely rare. The course of pediatric CSS is usually severe and often lethal. We present a case of a 13-year-old girl with a short history of asthma, marked eosinophilia, and multiorgan involvement. The extremely high level of blood eosinophilic granulocytes $\left(51.6 \times 10^{9} / \mathrm{L}\right)$ prompted a workup for eosinophilic leukemia before the diagnosis CSS could be made. Subsequently, the disease was successfully treated. This case report shows a classical case of childhood CSS, remarkable because of the presence of extreme hypereosinophilia. It underlines the importance of CSS as a lifethreatening cause of hypereosinophilia in children.
\end{abstract}

Keywords Childhood · Churg-Strauss syndrome · CSS · Hypereosinophilia

\section{Introduction}

Churg-Strauss syndrome (CSS), also called allergic granulomatous angiitis, is a systemic vasculitis of the small- and

E. R. Mutsaers · R. Witteveen • W. van den Bosch-Ruis •

M. A. van Houten

Department of Pediatrics, Spaarne Ziekenhuis,

Hoofddorp, The Netherlands

T. W. Kuijpers $\cdot$ J. M. van den Berg $(\varangle)$

Department of Pediatric Hematology, Immunology and Infectious

Diseases Emma Children's Hospital, Academic Medical Centre,

University of Amsterdam,

Meibergdreef 9,

1100 DD Amsterdam, The Netherlands

e-mail: j.m.vandenberg@amc.nl medium-sized vessels and is associated with the presence of antineutrophil cytoplasmatic antibodies (ANCA) against myeloperoxidase (MPO) $[1,2]$. The key features of this syndrome are de novo asthma and eosinophilia combined with vasculitic organ manifestations. The etiology of CSS is unknown [3]. The clinical presentation is variable and depends on the stage of the illness and previous use of corticosteroids [4]. CSS mostly presents in middle-aged individuals with a brief history of asthma. The annual incidence of CSS in adults ranges between 0.5 and 3.1 cases per million per year [5]. In children, the incidence is unknown but is presumably very low with only 33 cases reported in the literature $[4,6]$.

In this case report, we present a 13-year-old girl with a short history of asthma and extreme leukocytosis consisting mainly of eosinophilic granulocytes $\left(51.6 \times 10^{9} / \mathrm{L}\right)$. This number exceeds by far the amount of eosinophilic granulocytes reported in earlier case reports. Therefore, leukemia as the underlying cause was excluded before adequate treatment for CSS could be started. The diagnosis CSS was established by blood tests and a tissue biopsy.

This case illustrates that an extremely high white blood cell count with marked peripheral hypereosinophilia in childhood can be the presenting symptom of Churg-Strauss syndrome.

Because of its extremely low incidence in childhood, the diagnosis can be difficult while delay of adequate treatment may result in unnecessary morbidity and even mortality.

\section{Case report}

A 13-year-old girl presented at the pediatric department of a general hospital with malaise, dyspnea, diarrhea, and wasting. Three months earlier, she had been diagnosed 
with allergic asthma. Her previous medical history had been uneventful with no earlier signs of obstructive airway disease. The family history was unremarkable.

Therapy for asthma had been started consisting of combined inhalation therapy with formoterole/budesonide. In the following months, she developed progressive fatigue, occasional nasal bleeding, painful swelling of the joints, small transient ulcerations of the skin, and tingling with a sensation of numbness of the right foot. Twice, she had been treated with a short course of prednisolone because an increase of respiratory distress was interpreted as an exacerbation of asthma, which resulted in a temporary relief. A few days prior to admission, the complaints had suddenly increased when she developed watery diarrhea.

Physical examination showed tachydyspnea with rales, mild expiratory wheezing, and dark purple lesions on the extremities. Both hands showed arthritis of the proximal interphalangeal joints with interdigital pustules on the right hand. There was a slight proptosis of the left eye.

Initial laboratory studies revealed an ESR of $80 \mathrm{~mm} / \mathrm{h}$ (reference range, $1-15 \mathrm{~mm} / \mathrm{h}$ ), a white blood cell count of $65.8 \times 10^{9} / \mathrm{L}$ (reference range, $4-14 \times 10^{9} / \mathrm{L}$ ) with $14 \%$ neutrophils, $15 \%$ lymphocytes, $67 \%$ eosinophils (absolute count of $44 \times 10^{9} / \mathrm{L}$ ), $6 \%$ monocytes, and $0 \%$ basophils. Urinalysis was normal with no signs of proteinuria.

Because of the extreme hypereosinophilia combined with numerous aspecific symptoms, an eosinophilic leukemia had to be excluded. The girl was immediately transferred to the pediatric oncology unit of an academic hospital where a bone marrow aspiration was performed next day. This showed, apart from many normal eosinophilic granulocytes, no abnormalities.

Chest radiography (Fig. 1a) showed interstitial and peribronchial infiltration; a computed tomography (CT) scan (Fig. 1b) of the thorax revealed bronchiectasis with mucus impaction and multiple granulomatous nodules.
Electro- and echocardiogram and abdominal ultrasound revealed no abnormalities. An MRI and CT scan of the head showed a lesion in the left orbita. Neurological examination showed signs of mononeuritis of the left $n$. medialis. However, an EMG was normal.

Extensive cultures and serologic tests were negative for infectious diseases caused by bacteria, viruses, parasites, or fungi. A biopsy of the nasal mucosa revealed eosinophilic vasculitis. A gastroduodenoscopy was not performed because of the high risk of perforation.

Both clinical symptoms and test results fitted with the diagnosis CSS. This diagnosis was confirmed when laboratory results showed a highly increased titer for ANCA with a perinuclear pattern at immunofluorescence (1:1280). An ELISA showed the presence of antibodies against MPO (1072 kAU/L, normal 0-15) with a negative ELISA for ANCA against proteinase 3 (PR3) and a highly elevated $\operatorname{IgE}(5035 \mathrm{kU} / \mathrm{L}$, normal 0-100). Also, the rheumatoid factor as measured by ELISA was highly increased (2560 kU/L, normal 0-12.5) with negative antiCCP, ANA, and anti-double stranded DNA.

Subsequently, high-dose corticosteroid pulse therapy was started followed by oral prednisolone. The blood eosinophilic count dropped from a maximum of $51.6 \times$ $10^{9} / \mathrm{L}$ to $0.04 \times 10^{9} / \mathrm{L}$, and all signs of the disease disappeared completely in a few days.

The patient was discharged from the hospital in an excellent condition. The patient is now in a good clinical condition with normal spirometric tests and a normal chest $\mathrm{X}$-ray.

\section{Discussion}

We have described a pediatric patient with CSS characterized by a pseudoleukemic reaction with extreme eosino-
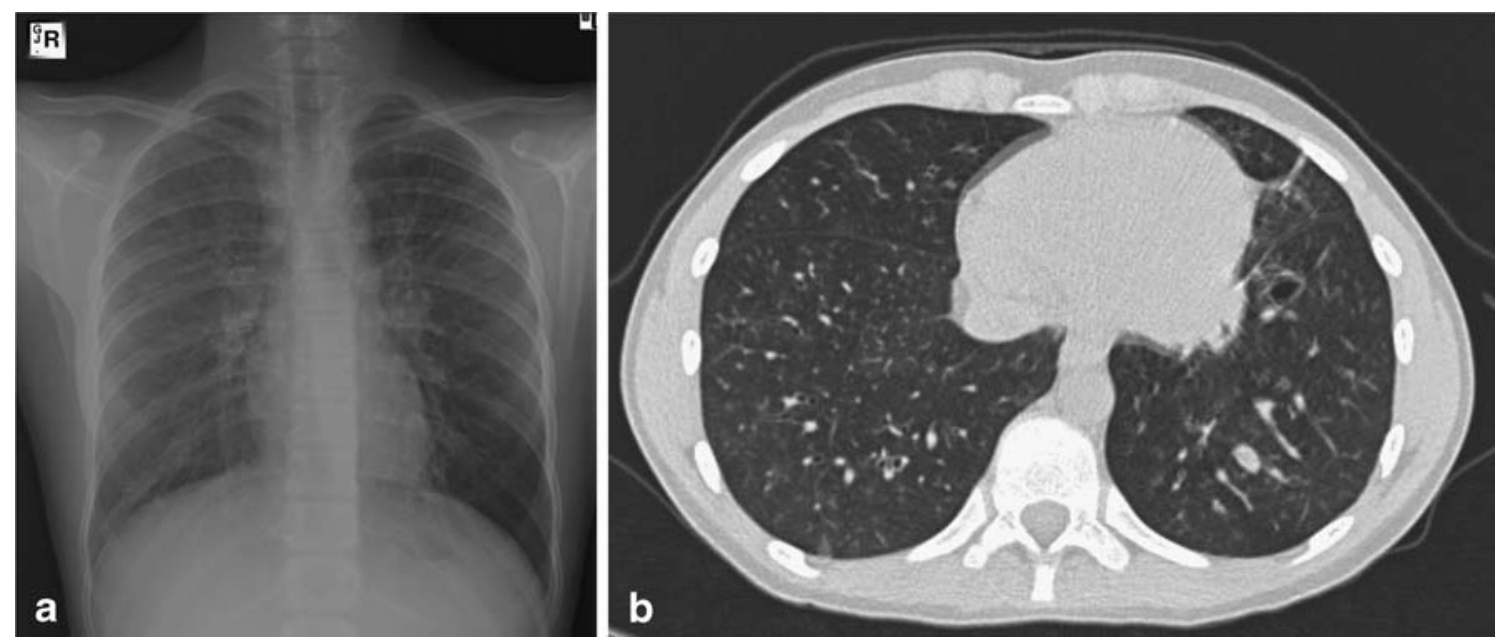

Fig. 1 a Chest radiograph. b CT scan of the thorax 
philia with pulmonary, gastrointestinal, nasal, cutaneous, and orbital involvement, clinical signs of a mild arthritis and mononeuritis multiplex. The diagnosis of this lifethreatening disease was difficult because CSS is extremely rare in childhood. Moreover, the number of eosinophils exceeded by far the reported levels in the literature, suggesting leukemia.

In 1990, the American College of Rheumatology (ACR) developed specific clinical criteria for the classification of Churg-Strauss syndrome [7]. The ACR criteria are asthma, eosinophilia greater than $10 \%$ on differential white blood cell count, neuropathy, pulmonary infiltrates, paranasal sinus abnormalities, and a biopsy containing extravascular eosinophils. The presence of four or more of the six ACR criteria is reported to yield a diagnostic sensitivity of $85 \%$ and a specificity of $99.7 \%$ for the diagnosis of CSS [7]. Our patient met five of the six criteria; only paranasal sinus abnormalities could not be substantiated. The positive perinuclear immunofluorescence for ANCA and strongly elevated anti-MPO ANCA in the ELISA confirmed the diagnosis CSS. A positive ELISA for anti-MPO ANCA is highly specific [8] and distinguishes between CSS and diseases in which the other important ANCA, anti-PR3 is positive, most importantly $\mathrm{M}$. Wegener.

Although the etiology of CSS is still unknown, it is clearly an autoimmune process with an essential role for ANCA [3]. Three sequential phases have been described in adult CSS [9]: the prodromal phase characterized by lateonset asthma preceded by allergic rhinitis in patients with no atopic constitution. The second phase includes peripheral blood eosinophilia and eosinophilic tissue infiltration, followed by a life threatening third phase which is characterized by systemic vasculitis with multiorgan pathology including cutaneous, cardiac, pulmonary, gastrointestinal, musculoskeletal, central, and peripheral nervous system and renal disease [9]. Cardiac, renal, gastrointestinal, and central nervous system involvement causes significant mortality [10]. Outcome in childhood CSS is significantly worse with a $19 \%$ mortality rate in comparison with a 5\% mortality rate in adult CSS [6]. Most reported causes of death in children with CSS are cardiac failure due to cardiomyopathy, intestinal perforation, and respiratory failure [10]. Treatment with corticosteroids is often successful with better outcome if started early [6].

Available data on childhood CSS are limited and generally consist of single case reports. Establishment of pediatric registries for vasculitis and availability of classification criteria will allow for better characterization of CSS presenting in childhood [11].

A recent review of 33 pediatric case reports outlined the clinical features of childhood CSS and compared them to adults [6]. Significant asthma and eosinophilia were found in all pediatric cases. The highest absolute eosinophilic count reported in all ages was $28.8 \times 10^{9} / \mathrm{L}[2,6]$. In our patient, the most striking feature was leukocytosis in leukemic ranges $\left(65.8 \times 10^{9} / \mathrm{L}\right)$ with an excessively high number of eosinophils $\left(51.6 \times 10^{9} / \mathrm{L}\right)$. Many aspects of CSS are similar in adult and pediatric patients [6]. However, cardiorespiratory manifestations may be seen more frequently in children while peripheral nerve, musculoskeletal symptoms, and arthralgia may be less common [6]. Although CSS is a rare disease, it has to be considered by clinicians in children presenting with de novo asthma and hypereosinophilia. Early diagnosis will lead to adequate treatment and therefore, prevention of morbidity and even mortality.

\section{Disclosures None}

Open Access This article is distributed under the terms of the Creative Commons Attribution Noncommercial License which permits any noncommercial use, distribution, and reproduction in any medium, provided the original author(s) and source are credited.

\section{References}

1. Churg J, Strauss L (1951) Allergic granulomatosis, allergic angiitis, and periarteritis nodosa. Am J Pathol 27:277-301

2. Sinico RA, Di Toma L, Maggiore U et al (2005) Prevalence and clinical significance of antineutrophil cytoplasmic antibodies in Churg-Strauss syndrome. Arthritis Rheum 52:2926-2935

3. Hellmich B, Ehlers S, Csernok E, Gross WL (2003) Update on the pathogenesis of Churg Strauss syndrome. Clin Exp Rheumatol 21:S69

4. Boyer D, Vargas SO, Slattery D, Rivera-Sanchez YM, Colin AA (2006) Churg-Strauss syndrome in children: a clinical and pathological review. Pediatrics 118:e914-e920

5. Lane SE, Watts R, Scott DG (2005) Epidemiology of systemic vasculitis. Curr Rheumatol Rep 7:270-275

6. Zwerina J, Eger G, Englbrecht M, Manger B, Schett G (2008) Churg-Strauss syndrome in childhood: A systematic literature review and clinical comparison with adult patients. Semin Arthritis Rheum July 16 (epub ahead of print)

7. Masi AT, Hunder GG, Lie JT et al (1990) The American College of Rheumatology 1990 criteria for the classification of ChurgStrauss syndrome (allergic granulomatosis and angiitis). Arthritis Rheum 33:1094-1100

8. Hagen EC, Andrassay K, Csernok E et al (1996) Development and standardization of solid phase assays for the detection of antineutrophil cytoplasmic antibodies (ANCA). A report on the second phase of an international cooperative study on the standardization of ANCA assays. J Immunol Methods 196:1

9. Lanham JG, Elkon KB, Pusey CD, Hughes GR (1984) Systemic vasculitis with asthma and eosinophilia: a clinical approach to the Churg-Strauss syndrome. Medicine (Baltimore) 63:65-81

10. Guillevin L, Lhote F, Gayraud M, Cohen P, Jarrousse B, Lortholary O, Thibult N, Casassus P (1996) Prognostic factors in polyarteritis nodosa and Churg-Strauss syndrome. A prospective study in 342 patients. Medicine (Baltimore) 75:17-28

11. Wilkinson NM, Page J, Uribe AG, Espinosa V, Cabral DA (2007) Establishment of a pilot pediatric registry for chronic vasculitis is both essential and feasible: a Childhood Arthritis and Rheumatology Alliance (CARRA) survey. J Rheumatol 34:224-226 